\title{
Design of dampers for structures based on optimal control theory
}

\author{
Chin-Hsiung Loh ${ }^{1,2, *, \dagger}$, Pei-Yang $\operatorname{Lin}^{1, \ddagger}$ and Nan-Hau Chung ${ }^{2, \S}$ \\ ${ }^{1}$ Department of Civil Engineering, National Taiwan University, Taipei, Taiwan \\ ${ }^{2}$ National Center for Research on Earthquake Engineering, 200 Sec. 3, Hsinhai Road, Taipei, Taiwan
}

\begin{abstract}
SUMMARY
The aim of this paper was to propose a design guideline for using visco-elastic dampers for the control of building structures subjected to earthquake loading as well as suspension roof structures subjected to wind loading. The active control algorithm was used to calculate the control forces. Based on the single-mode approach the control forces were transformed to the forces which visco-elastic dampers can provide. Application of the method to the design of the building structure with passive damping devices in the bracing system and to the suspension roof with dampers was studied. Through the application of optimal control theory a systematic design procedure to implement dampers in structures is proposed. Copyright (C) 2000 John Wiley \& Sons, Ltd.
\end{abstract}

KEY WORDS: optimal control algorithm; viscoelastic damper; structural dynamics

\section{INTRODUCTION}

For the past few years there has been a rapid growth in the development and application of structural energy dissipation devices for earthquake hazard mitigation. The idea of these devices is to enhance the structural energy dissipation capacity against moderate and strong earthquakes, and to reduce seismic risk without compromising safety and economy of the structure itself. The use of energy dissipation devices (EDDs) for vibration reduction of structures has been considered in the literature and has already been proposed for retrofit upgrading of existing buildings and for new constructions [1-9]. These energy dissipation devices include: viscoelastic dampers, friction devices and plastically deforming metals. Most of them have also been considered for seismicresistant design. Among the variety of energy-dissipation devices, viscoelastic (VE) dampers are one of the successful devices employed for seismic hazard mitigation application.

\footnotetext{
* Correspondence to: Chin-Hsiung Loh, National Center for Research on Earthquake Engineering, 200 Sec. 3, Hsinhai Road, Taipei, Taiwan.

$\dagger$ Professor and Director of National Center for Research on Earthquake Engineering, Taiwan.

‡ Graduated student.

$\S$ Research assistant.
}

Copyright (C) 2000 John Wiley \& Sons, Ltd.

Received 6 August 1999

Revised 25 February 2000

Accepted 22 March 2000 
In the design of structure with VE dampers modifications to the modal damping and stiffness due to addition of VE dampers can be obtained by the modal strain energy method [3]. These viscoelastic-type damping devices (passive devices) pose force-displacement relationship which can be approximated by

$$
F(t)=\bar{k}(\omega) x(t)+\bar{c}(\omega) \dot{x}(t)
$$

where $\bar{k}(\omega)$ and $\bar{c}(\omega)$ are frequency dependent. The force-displacement response of a viscoelastic damper is strongly dependent on ambient temperature, excitation frequency and shear strain amplitude. To simplify the viscoelastic material, the damper is modeled as an elastic spring and a dashpot acting in parallel. The force in the damper is the sum of the elastic and the viscous forces, and both the elements are subjected to the same deformation. The damper force can be approximated by

$$
F_{\mathrm{d}}=k_{\mathrm{d}} x(t)+c_{\mathrm{d}} \dot{x}(t)
$$

where $k_{\mathrm{d}}$ and $c_{\mathrm{d}}$ are constant parameters. The design and distribution of individual viscoelastic dampers and associated bracing is based on a simple approach that includes uniform proportioning of the dampers over the height of the structure [2], a design based on an assumed mode shape of the viscoelastically damped structure, and a distribution proportional to the storey stiffness of the primary structure [10]. Recently, the optimal linear control approach was used to determine the constant coefficients for the damping devices [11].

This paper was to conduct the design of viscoelastic damper by using the active control algorithm. Through simulation study a building structure with dampers as bracing system and a suspension roof with vertical dampers were studied. Comparison on the properties of the designed damper was also made by using different control algorithms.

\section{DEVELOPMENT OF CONTROL STRATEGY}

Active control has been used to mitigate earthquake excitations in numerical and experimental studies. Various control algorithms have been proposed in both experimental and practical applications. They include LQR, predict control, modal control, sliding mode control [12] and $\mathrm{H}$-infinity control [13], etc. Each control algorithm has its own distinct features and among them direct measurement feedback control can be used with most of them. Consider an $n$-degree of freedom linear system subjected to seismic excitation. The vector equation of motion is given (in state-space form) as

$$
\dot{Z}(t)=A Z(t)+B U(t)+E W(t)
$$

where

$$
Z(t)=\left\{\begin{array}{l}
X(t) \\
\dot{X}(t)
\end{array}\right\}, \quad A=\left[\begin{array}{cc}
\underline{0} & I \\
-M^{-1} K & -M^{-1} C
\end{array}\right], \quad B=\left[\begin{array}{c}
\underline{0} \\
M^{-1} H_{1}
\end{array}\right], \quad E=\left[\begin{array}{c}
\underline{0} \\
M^{-1} H_{2}
\end{array}\right]
$$


in which $A$ is the system matrix, $U(t)$ is the control force vector and $W(t)$ is the excitations. Since Equation (3) represents the dynamics of the complete structure, it is called the full-order system. The discrete form of Equation (1) can be expressed as

$$
Z[k+1]=A_{\mathrm{d}} Z[k]+B_{\mathrm{d}} U[k]+E_{\mathrm{d}} W[k]
$$

where $A_{\mathrm{d}}=\exp [A \Delta t], B_{\mathrm{d}}=A^{-1}\left(A_{\mathrm{d}}-I\right) B, E_{\mathrm{d}}=A^{-1}\left(A_{\mathrm{d}}-I\right) E$. Now define the output vector $\bar{Y}(t)$ which contains $m$ measurement $(m<2 n)$ and the relationship between measurement and the state vector is expressed as

$$
\bar{Y}(t)=C Z(t)
$$

where the $C(m \times 2 n)$ matrix is referred to as the observation matrix.

Based on the system equation of motion with the consideration of the direct output-feedback control, two different control algorithms are introduced in this study. By using optimal control theory the calculated control gain was converted to the equivalent viscous damping using a single-mode approach. The following two control algorithms are used which are both based on the direct output-feedback signals.

\subsection{Static-output-feedback LQR control [14]}

The static-output-feedback control uses the measured output to compute the control force directly. This method is derived where the control commands are directly generated from the sensor signals measured only at limited locations of controlled structures. It is different from the dynamic-output-feedback control in which the dynamic condensation was used to reduce the degree-of-freedom of the structure system and then the predict-type Kalman filter was also used to predict the full-state response of the system using measurement. The performance index to be minimized in the static-output-feedback LQR optimal controller is given by

$$
J=Z^{\mathrm{T}}(t) Q Z(t)+U^{\mathrm{T}}(t) R U(t)+\lambda(t)\{A Z(t)+B U(t)-\dot{Z}(t)\}
$$

A minimization of the performance index $J$ subjected to the constraint can be expressed as follows:

$$
\begin{aligned}
& \frac{\partial J}{\partial Z(t)}=0 \Rightarrow Q Z(t)+A^{\mathrm{T}} \lambda(t)+\dot{\lambda}(t)=0 \\
& \frac{\partial J}{\partial U(t)}=0 \Rightarrow U(t)=-R^{-1} B^{\mathrm{T}} \lambda(t)
\end{aligned}
$$

To consider the limited measurements, set $\lambda(t)=P C Z(t)=P Y(t)$, where $C$ is the transformation matrix which transfers the full-state vector to the measurement output and $P$ is an unknown matrix that has to be determined. By substituting $\lambda(t)$ into Equation (7) the following equation is derived:

$$
Q Z(t)+A^{\mathrm{T}} P C Z(t)+P C A Z(t)-P C B R^{-1} B^{\mathrm{T}} P C Z(t)=0
$$


Setting $P_{r}=P C$, Equation (8) can be reduced to the standard Ricatti equation

$$
Q+A^{\mathrm{T}} P_{\mathrm{r}}+P_{\mathrm{r}} A-P_{\mathrm{r}} B R^{-1} B^{\mathrm{T}} P_{\mathrm{r}}=0
$$

In order to determine the control force $\left(U(t)=-R^{-1} B^{\mathrm{T}} \lambda(t)\right)$, it is necessary to find the $P$-matrix and $P_{\mathrm{r}}$, which can be obtained from the Ricatti equation as shown in Equation (9). A least-squares minimization method was proposed to solve $P_{\mathrm{r}}$ from the equation $P_{\mathrm{r}}-P C=0$. By defining another objective function $J_{i}=\left(P_{i} C-P_{\mathrm{r} i}\right) \Theta\left(P_{i} C-P_{\mathrm{r} i}\right)^{\mathrm{T}}$, and then through minimization, one can obtain

$$
P_{i}=\left(P_{\mathrm{r} i} \Theta C^{\mathrm{T}}\right)\left(C \Theta C^{\mathrm{T}}\right)^{-1}
$$

where $P_{i}$ is the $i$ th column of $P$ and $P_{\mathrm{r} i}$ is the $i$ th column of $P_{\mathrm{r}}$, and $\Theta$ is the weighting factor. Finally, the control force can be obtained as

$$
U(t)=-R^{-1} B^{\mathrm{T}}\left[\left(P_{\mathrm{r}} \Theta C^{\mathrm{T}}\right)\left(C \Theta C^{\mathrm{T}}\right)^{-1}\right] Y(t)=G Y(t)
$$

\subsection{Modal control with direct-output-feedback (modal control) [15]}

Modal control is the method of computing the gain matrix, $G$, to achieve the desired modal properties, i.e. frequency, damping ratio and modal shape. Because of limited measurements, one can only assign $r$ modal properties ( $r$ is the number of sensors). Herein the sensor signals measure only velocity $\dot{x}_{1}$ and displacement $x_{1}$. Let $\lambda_{i}$ and $\mu_{i}$ (where $i=1-r$ ) be the assigned eigenvalues and eigenvectors, respectively. Therefore, the state equation of motion of the control system can be expressed as

$$
(A+B G C) \mu_{i}=\lambda_{i} \mu_{i}
$$

where $C$ is the transformation matrix which transfers the state vector to the measurement output and $G$ is the control gain. Equation (12) can be separated into two parts as follows:

$$
\begin{aligned}
& \left(A_{1}+B_{1} G C\right) \mu_{i}=\lambda_{i} \mu_{i}^{1} \\
& \left(A_{2}+B_{2} G C\right) \mu_{i}=\lambda_{i} \mu_{i}^{2}
\end{aligned}
$$

where

$$
A=\left[\begin{array}{l}
A_{1} \\
A_{2}
\end{array}\right], \quad B=\left[\begin{array}{l}
B_{1} \\
B_{2}
\end{array}\right], \quad \mu_{i}=\left[\begin{array}{l}
\mu_{i}^{1} \\
\mu_{i}^{2}
\end{array}\right] .
$$

The dimensions of $A_{i}$ and $B_{i}$ are $p \times 2 n, p \times p$, respectively ( $p$ is the number of controllers). First assigning eigenvalues and eigenvectors in Equation (13) and combining all the $r$ equations, the following matrix form is derived:

$$
\left(A_{1}+B_{1} G C\right) U_{\mathrm{c}}=Z_{\mathrm{c}} \operatorname{diag}\left(\lambda_{i}\right)_{\mathrm{c}}
$$


where

$$
U_{\mathrm{c}}=\left[\mu_{1} \mu_{2} \ldots \mu_{r}\right]_{2 n \times r}, \quad \operatorname{diag}\left(\lambda_{i}\right)_{\mathrm{c}}=\left[\begin{array}{cccc}
\lambda_{1} & 0 & 0 & 0 \\
0 & \lambda_{2} & 0 & 0 \\
0 & 0 & \ddots & 0 \\
0 & 0 & 0 & \lambda_{r}
\end{array}\right]_{r \times r}
$$

$Z_{\mathrm{c}}=\left[\mu_{1}^{1} \mu_{2}^{1} \ldots \mu_{r}^{1}\right]_{2 n \times r}$. Then the gain matrix, $G$, is given by

$$
G=B_{1}^{-1}\left(Z_{\mathrm{c}} \operatorname{diag}\left(\lambda_{i}\right)_{\mathrm{c}}-A_{1} U_{\mathrm{c}}\right)\left(C U_{\mathrm{c}}\right)^{-1}
$$

Note that $B_{1}$ must be a non-singular matrix and $r$ must be an even number. Similarly, Equation (14) can be derived by the same procedure as Equation (13) and the following relationship can be obtained:

$$
\left(A_{2}+B_{2} G C\right) U_{\mathrm{c}}=W_{\mathrm{c}} \operatorname{diag}\left(\lambda_{i}\right)_{\mathrm{c}}
$$

where $W_{\mathrm{c}}=\left[\mu_{1}^{2} \mu_{2}^{2} \ldots \mu_{r \times r}^{2}\right]_{(2 n-p) \times r}$. Substituting Equation (16) into Equation (17), one can obtain the following equation:

$$
\left(A_{2}-B_{2} B_{1}^{-1} A_{1}\right) U_{\mathrm{c}}+B_{2} B_{1}^{-1} Z_{\mathrm{c}} \operatorname{diag}\left(\lambda_{i}\right)_{\mathrm{c}}=W_{\mathrm{c}} \operatorname{diag}\left(\lambda_{i}\right)
$$

Let

$$
\begin{gathered}
U_{\mathrm{c}}=\left[\begin{array}{l}
Z_{\mathrm{c}} \\
W_{\mathrm{c}}
\end{array}\right], \quad A=\left[\begin{array}{ll}
A_{11} & A_{12} \\
A_{21} & A_{22}
\end{array}\right], S=B_{2} B_{1}^{-1} \text { : then Equation (18) can be derived as follows: } \\
\left(A_{21}-S A_{11}\right) Z_{\mathrm{c}}+\left(A_{22}-S A_{12}\right) W_{\mathrm{c}}+S Z_{\mathrm{c}} \operatorname{diag}\left(\lambda_{i}\right)_{\mathrm{c}}=W_{\mathrm{c}} \operatorname{diag}\left(\lambda_{i}\right)_{\mathrm{c}}
\end{gathered}
$$

Also, Equation (19) can be further simplified as

$$
W_{\mathrm{c}} \operatorname{diag}\left(\lambda_{i}\right)-F W_{\mathrm{c}}=H Z_{\mathrm{c}}+S Z_{\mathrm{c}} \operatorname{diag}\left(\lambda_{i}\right)_{\mathrm{c}}
$$

where $H=\left(A_{22}-S A_{12}\right), F=\left(A_{22}-S A_{12}\right)$. Now considering the $i$ th mode, the following relationship can be derived:

$$
\left(\lambda_{i} I-F\right) \mu_{i}^{2}=\left(H+\lambda_{i} S\right) \mu_{i}^{1}
$$

Equation (21) implies that not all the elements in the assigned $r$ eigenvector can be arbitrarily prescribed, but only $p$ elements in each of the eigenvectors can be freely chosen.

To find a suitable eigenvector that satisfies the condition shown in Equation (21), a performance index in terms of $\mu_{i}$ and $\mu_{i}^{\mathrm{d}}$ is expressed as

$$
J=\left\|\mu_{i}^{\mathrm{d}}-\mu_{i}\right\|^{2}
$$


where $\mu_{i}^{\mathrm{d}}$ is the desired eigenvector. Finally, the best achievable eigenvector, $\mu_{j}$, can be obtained through minimization of the performance index, Equation (22).

\section{DESIGN OF VE DAMPER BY SINGLE-MODE APPROACH}

The active control force obtained from the above two methods can be expressed as

$$
U(t)=G Z(t)=G_{X} X(t)+G_{\dot{X}} \dot{X}(t)
$$

where $G_{X}$ and $G_{\dot{X}}$ are the control gains related to the displacement and velocity responses. In the active control case, the equation of motion can be written as

$$
M * \ddot{X}(t)+C^{*} \dot{X}(t)+K^{*} X(t)=B G_{\dot{X}} \dot{X}(t)+B G_{X} X(t)+E^{*} W(t)
$$

On the contrary, if the passive control algorithm is used to control a structure through the use of additional damping $[\Delta C]$ and stiffness matrix $[\Delta K]$, the following equation of motion can be modified as

$$
M * \ddot{X}(t)+C^{*} \dot{X}(t)+K^{*} X(t)=-[\Delta C] \dot{X}(t)-[\Delta K] X(t)+E^{*} W(t)
$$

To minimize the difference between the system equation using active control strategy and the equation using passive control strategy the following equation should be satisfied:

$$
\left[-B G_{\dot{X}}\right] \dot{X}=[\Delta C] \dot{X},\left[-B G_{X}\right] X=[\Delta K] X
$$

Expressing the response in modal co-ordinates, one can obtain

$$
\begin{gathered}
X(t)=\left\lfloor\Phi_{1} Y_{1}(t)+\Phi_{2} Y_{2}(t)+\cdots \Phi_{n} Y_{n}(t)\right\rfloor \\
\dot{X}(t)=\left[\Phi_{1} \omega_{1} Y_{1}(t)+\Phi_{2} \omega_{2} Y_{2}(t)+\cdots \Phi_{n} \omega_{n} Y_{n}(t)\right]
\end{gathered}
$$

where $\Phi_{1}, \Phi_{2}, \ldots, \Phi_{n}$ are the mode shapes of the dynamic system, and $Y_{1}(t), Y_{2}(t), \ldots, Y_{n}(t)$ are the responses in modal co-ordinate.

Using the single-mode approach method, and assuming that only one mode (mode $j$ ) had the major contribution to the system, it follows that

$$
X(t)=\Phi_{j} Y_{j}(t) ; \dot{X}(t)=\Phi_{j} \omega_{j} Y(t)
$$

Equation (26) can be rewritten as

$$
\left[-B G_{\dot{X}}\right] \Phi_{j} \omega_{j} Y_{j}=[\Delta C] \Phi_{j} \omega_{j} Y_{j} ;\left[-B G_{X}\right] \Phi_{j} Y_{j}=[\Delta K] \Phi_{j} Y_{j}
$$


If one selects $[\Delta C]$ and $[\Delta K]$ as diagonal matrices (neglecting the off-diagonal terms) then the following result can be obtained:

$$
\Delta C_{i i}=\frac{\sum_{k=1}^{n}\left[-B G_{\dot{X}}\right]_{i k} \Phi_{k j}}{\Phi_{i j}} ; \quad \Delta K_{i i}=\frac{\sum_{k=1}^{n}\left[-B G_{X}\right]_{i k} \Phi_{k j}}{\Phi_{i j}}
$$

Based on Equation (30), the extra damping and stiffness that will be added to the structure can be calculated with the information provided by the optimal control theory.

Now considering a VE damper subjected to a harmonic sine wave, the damper strain can be expressed as

$$
\begin{aligned}
& \gamma(t)=\gamma_{0} \mathrm{e}^{i \omega t}=\gamma_{0}[\cos (\omega t)+i \sin (\omega t)] \\
& \dot{\gamma}(t)=i \omega \gamma_{0} \mathrm{e}^{i \omega t}=\gamma_{0} \omega[-\sin (\omega t)+i \cos (\omega t)]
\end{aligned}
$$

It is assumed that the damper shear modulus can be expressed as a complex shear modulus

$$
G^{*}=\left|G^{*}\right| \mathrm{e}^{\mathrm{i} \delta}=G^{\prime}(\omega)+\mathrm{i} G^{\prime \prime}(\omega)
$$

then the stress-strain relationship of the damper is

$$
\begin{aligned}
\tau(t)= & G^{*}(\omega) \gamma(t) \\
= & \gamma_{0}\left[G^{\prime}(\omega) \cos (\omega t)-G^{\prime \prime}(\omega) \sin (\omega t)\right] \\
& +i \gamma_{0}\left[G^{\prime}(\omega) \sin (\omega t)+G^{\prime \prime}(\omega) \cos (\omega t)\right]
\end{aligned}
$$

According to Equations (31) and (33), the following stress-strain relation formula can be found:

$$
\tau(t)=G^{\prime} \gamma(t)+\frac{G^{\prime \prime}}{\omega} \dot{\gamma}(t)
$$

It follows that

$$
F(t)=\frac{G^{\prime}(\omega) n A}{\Delta h} X(t)+\frac{G^{\prime \prime}(\omega) n A}{\omega \Delta h} \dot{X}(t)
$$

where $X(t)=\gamma(t) \Delta h, \dot{X}(t)=\dot{\gamma} \Delta h, F(t)=\tau(t)^{*} A$. In addition, $A$ and $\Delta h$ are the area and thickness of VE damper and $n$ is the number of layers. From Equation (35) a force-displacement relationship was found. With this relationship one can design an appropriate $n, A$ and $\Delta h$ to minimize the following equations:

$$
J_{1}=\Delta C_{i i}-\frac{G^{\prime \prime}(\omega) n A}{\omega \Delta h} ; \quad J_{2}=\Delta k_{i i}-\frac{G^{\prime}(\omega) n A}{\Delta h}
$$


and determine the damper size. It is necessary to select suitable values of $G^{\prime}(\omega)$ and $G^{\prime \prime}(\omega)$ for a specified damper, with $\omega$ determined as the dominant frequency of the Fourier spectrum of the damper force.

\section{NUMERICAL EXAMPLES}

\subsection{Example 1: Building structure with passive damping devices in bracing system}

Four 5-storey building structures with first structural periods of $0.53,1.0,3.0$ and $5.0 \mathrm{~s}$, respectively, are designed. Table I shows the comparison of the structural periods among the four different structures. The damping ratios for all these structures are assumed to be $1 \%$ critical damping.

Two different earthquake ground motions are considered, i.e., Kobe earthquake and Landers earthquake (all normalized to 100 gal), as input motion at the base of the building. Based on the two control algorithms (i.e. LQR control and modal control) the design of dampers for these four kinds of structures was considered. It is assumed that the passive damping devices in bracing system are implemented in each storey of the building. Table II shows the designed damping value by LQR and modal control algorithms for the four different structures. It is found that the damping value designed by the LQR method is quite uniform along the height of the building, while the damping value designed by the modal control method looks similar to the shape of first mode. But the total damping value for the building is similar for these two methods. Table III shows the natural periods and the damping ratios of each structure with the consideration of adding passive damping. The modal damping and frequency of the building structure are slightly modified if the LQR control method is used. Figure 1 shows the acceleration response spectra of the two input ground motions (normalized to 1.0g). For any structure, the damper coefficients designed by using either LQR control or modal control show similar control efficiency. In other words, the maximum response reductions by using both control algorithms show very little difference. Therefore, this paper shows only the result designed by using static-output-feedback LQR control. Under two different earthquake ground motions, Figure 2 shows the maximum response reductions for four different structures, respectively. From these tables and figures, two observations can be concluded

1. It can be seen from Table II that the added damper coefficients, designed by LQR control algorithm are almost the same for each floor, but those designed by modal control are

Table I. Natural period (s) and damping ratio (\%) of four different kinds of 5-storey building structures.

\begin{tabular}{|c|c|c|c|c|c|c|c|}
\hline \multicolumn{2}{|c|}{ Structure 1} & \multicolumn{2}{|c|}{ Structure 2} & \multicolumn{2}{|c|}{ Structure 3} & \multicolumn{2}{|c|}{ Structure 4} \\
\hline Period* & Damping & Period* & Damping & Period* & Damping & Period* & Damping \\
\hline 0.5306 & 1.00 & 1.0000 & 1.00 & 3.0000 & 1.00 & 5.0000 & 1.00 \\
\hline 0.1627 & 1.00 & 0.3066 & 1.00 & 0.9197 & 1.00 & 1.5329 & 1.00 \\
\hline 0.0860 & 1.00 & 0.1621 & 1.00 & 0.4863 & 1.00 & 0.8105 & 1.00 \\
\hline 0.0560 & 1.00 & 0.1055 & 1.00 & 0.3164 & 1.00 & 0.5273 & 1.00 \\
\hline 0.0427 & 1.00 & 0.0804 & 1.00 & 0.2412 & 1.00 & 0.4020 & 1.00 \\
\hline
\end{tabular}

* Period: in second. 
Table II. Calculated damping value $(\mathrm{kg} \mathrm{s} / \mathrm{m})$ in each floor for four different kinds of building structures.

\begin{tabular}{ccccc}
\hline Floor & Structure 1 & Structure 2 & Structure 3 & Structure 4 \\
\hline (a) Designed by LQR control & & \\
\hline \multicolumn{5}{l}{ 1 } \\
2 & 333.81 & 100.95 & 59.39 & 42.70 \\
2 & 326.70 & 100.18 & 58.11 & 41.45 \\
3 & 319.76 & 99.35 & 56.86 & 40.28 \\
4 & 314.12 & 98.65 & 55.85 & 39.35 \\
5 & 308.92 & 97.99 & 54.92 & 38.51 \\
Total & 1603.30 & 497.12 & 285.14 & 202.29 \\
\hline
\end{tabular}

(b) Designed by modal control

\begin{tabular}{crrrr}
\hline 1 & 521.52 & 168.43 & 96.25 & 64.96 \\
2 & 305.90 & 98.79 & 56.45 & 38.10 \\
3 & 276.59 & 89.32 & 51.04 & 34.45 \\
4 & 261.58 & 84.48 & 48.28 & 32.58 \\
5 & 223.02 & 72.02 & 41.16 & 27.78 \\
Total & 1588.60 & 513.04 & 293.18 & 197.89 \\
\hline
\end{tabular}

Table III. Natural period (s) and damping ratio (\%) of four different kinds of building structures under passive control (designed by LQR and modal control algorithms, respectively).

\begin{tabular}{|c|c|c|c|c|c|c|c|}
\hline \multicolumn{4}{|c|}{ Structure 1} & \multicolumn{4}{|c|}{ Structure 2} \\
\hline \multicolumn{2}{|c|}{ LQR control } & \multicolumn{2}{|c|}{ Modal control } & \multicolumn{2}{|c|}{ LQR control } & \multicolumn{2}{|c|}{ Modal control } \\
\hline Period & Damping & Period & Damping & Period & Damping & Period & Damping \\
\hline 0.5286 & 24.82 & 0.5306 & 24.00 & 0.9986 & 14.89 & 1.0000 & 15.00 \\
\hline 0.1596 & 60.57 & 0.1622 & 55.77 & 0.3050 & 36.03 & 0.3064 & 34.35 \\
\hline 0.0856 & 77.34 & 0.0843 & 70.94 & 0.1621 & 45.50 & 0.1614 & 43.55 \\
\hline 0.0571 & 81.46 & 0.0547 & 78.08 & 0.1059 & 47.83 & 0.1051 & 46.88 \\
\hline 0.0430 & 80.84 & 0.0446 & 72.95 & 0.0806 & 47.57 & 0.0811 & 45.07 \\
\hline \multicolumn{4}{|c|}{ Structure 3} & \multicolumn{4}{|c|}{ Structure 4} \\
\hline 2.9887 & 24.95 & 3.0000 & 25.00 & 4.9746 & 29.35 & 5.0000 & 28.00 \\
\hline 0.9022 & 60.89 & 0.9170 & 58.15 & 1.4837 & 71.55 & 1.5264 & 65.28 \\
\hline 0.4836 & 77.77 & 0.4745 & 73.97 & 0.7730 & 92.28 & 0.7722 & 82.88 \\
\hline 0.3233 & 81.92 & 0.3078 & 82.04 & 0.5665 & 98.35 & 0.5086 & 95.96 \\
\hline 0.2429 & 81.29 & 0.2549 & 75.81 & 0.4075 & 96.11 & 0.4394 & 83.11 \\
\hline
\end{tabular}

increasing with the number of floors. It just shows that different control algorithms will lead to different control parameters, i.e. damping coefficients, even if they have the same control efficiency.

2. As for building structure, both the active-control system and passive-bracing system designed by single-mode approach show similar control efficiency. 


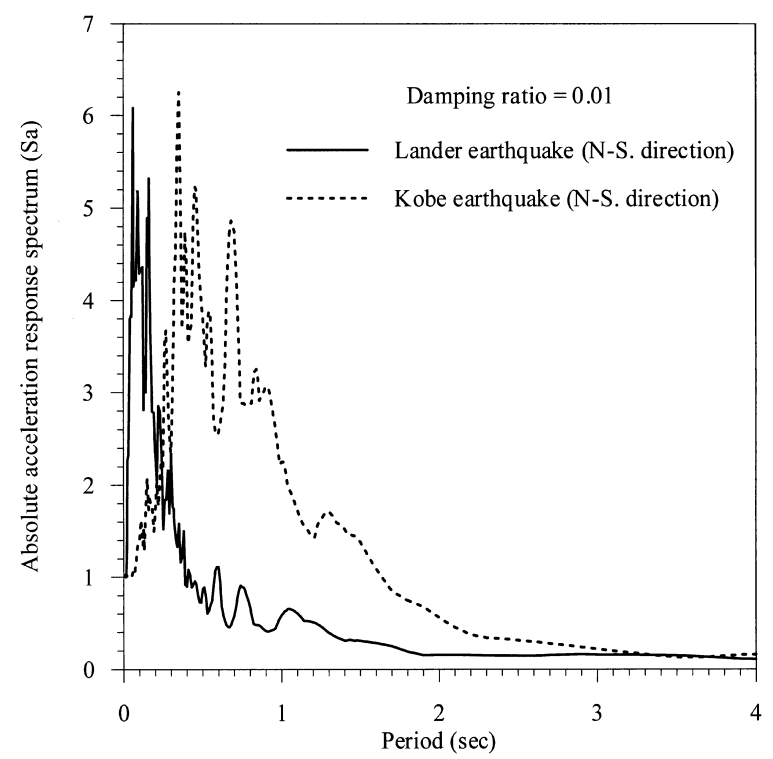

Figure 1. Absolute acceleration response spectrum $(\mathrm{Sa})$ of Lander earthquake and Kobe earthquake (JMA station).

\subsection{Example 2: Reduction of wind-induced vertical vibration of suspension roof with dampers}

Consider a suspension roof structure, as shown in Figure 3(a). Through SAP90 program, the structural system was condensed to a system with 24 nodes, and each node includes vertical, transverse and rotational directions of motion, as shown in Figure 3(b). In addition, the transverse direction is coupled with the rotational direction, so in this study there are 24 dofs in the vertical direction and 40 dofs in both the horizontal and rotational directions. The natural frequencies and damping ratios of the structure are shown in Tables IV(a) and (b). In this example the wind-induced vertical and rotational vibrations of the roof structure will be controlled. Based on the full-scale feedback LQR control, 48 dampers were designed and arranged in two rows in the vertical direction so that both vertical vibration as well as rotation of roof can be reduced. On the contrary, if direct-output-feedback control was used, then one can consider by using limited number of dampers. In this study, the static-output-feedback control was used, and only 8 dampers were considered instead of using 48 dampers. (The locations of dampers are in nodel point of $8,10,14$ and 16.$)$

In order to control the vertical and rotational responses, both the vertical vibration and horizontal vibration of the system were taken into consideration using active control formulation. Once the active control gains in two directions were calculated, singlemode approach was used to estimate passive damper coefficients. For the reduction of the vertical direction, generally the first mode was used in single-mode approach to design the damping coefficients of dampers. On the contrary, the second mode in the horizontal direction was used because in the horizontal direction the second mode was the lowest mode which contributed most in the rotational direction. Finally, a pair of vertical dampers in each nodal point (or in nodes 8, 10, 14, 16 for an 8-damper system) was designed. The dampers were 

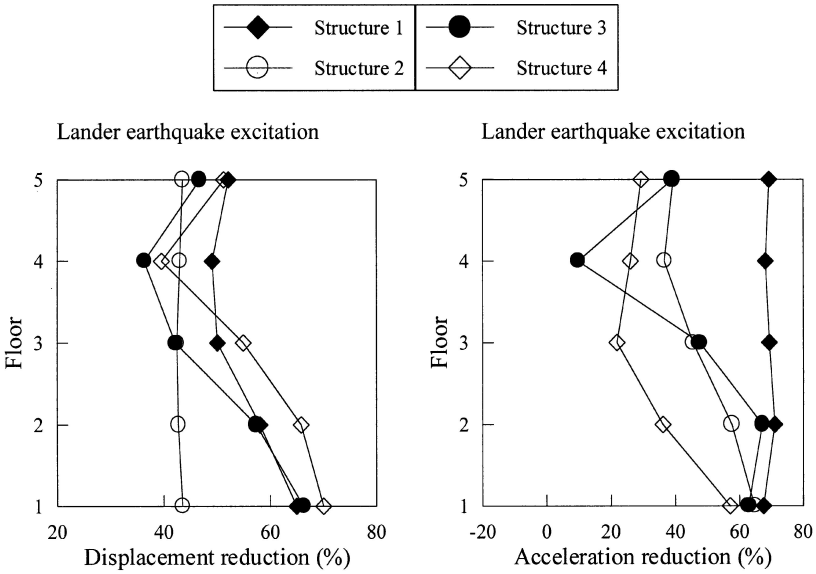

Kobe earthquake excitation Kobe earthquake excitation
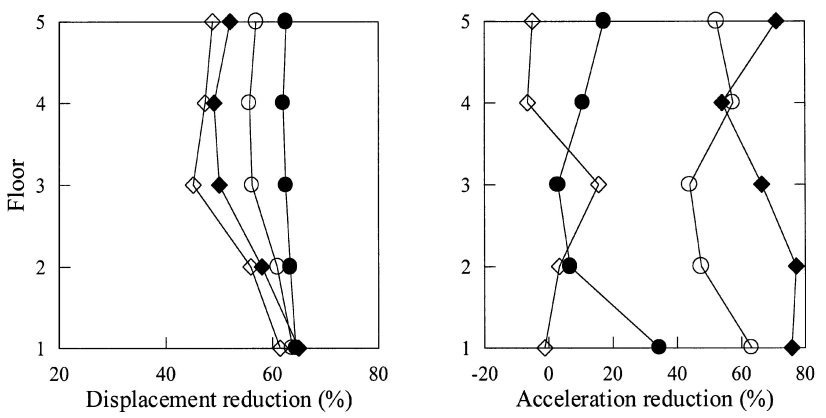

Figure 2. Displacement and acceleration reduction percentages of different structures (Structure 1-4) with passive control (designed by LQR control).

arranged in the vertical direction, but separated with two extended arms $l$, as shown in Figure 4 . Through such an arrangement both vertical and rotational vibrations of the roof can be controlled.

It was assumed that the roof structure was subjected to wind loading in the transverse direction. The turbulence wind velocity was simulated through random vibration approach. Figure 5 shows the power spectrum of simulated wind time history $\left(V_{\text {mean }}=40 \mathrm{~m} / \mathrm{s}\right)$. The damping coefficient and location of the 48-damper system are shown in Figure 6. In this figure, the apparent change of estimated damping value was found at nodes 4 and 21, which were the location of the hinge and roller of the suspension roof supported by the towers. The maximum vertical displacement of the centreline of the suspension roof (point A in Figure 4) under wind load is shown in Figure 7. In addition, the maximum vertical response, including rotational response, located $2.85 \mathrm{~m}$ away form the centreline is shown in Figure 8. Through such a designed method a good agreement was found between active and passive control. The proposed method of using design viscoelastic damper can reduce the vibration of structure almost to the same extent as active control even though only the single-mode approach was used. Figure 9 shows 

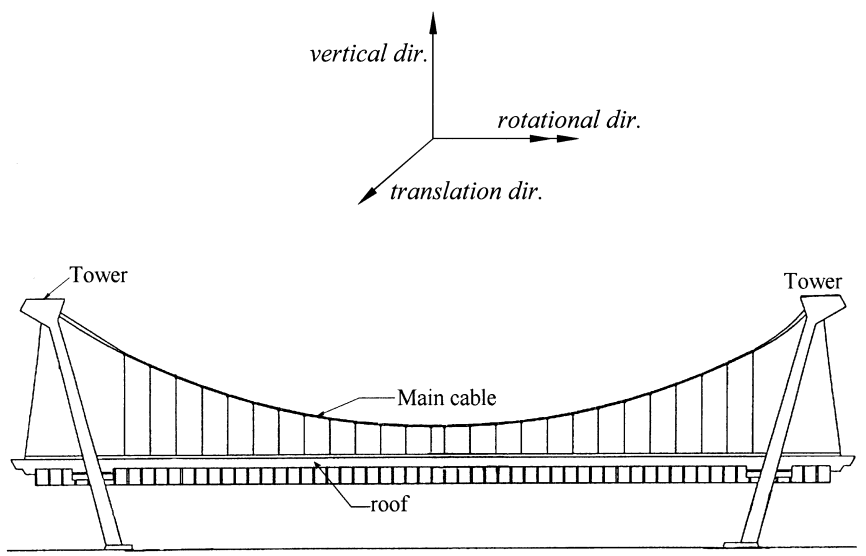

(a)

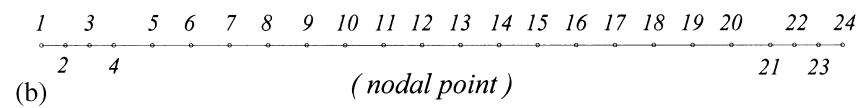

Figure 3. (a) The suspension roof system of Chientan station, Taipei Rapid Transit System. (b) Lump mass system diagram of suspension roof, Chientan station, Taipei Rapid Transit System.

Table IV. Structure parameters of Example 2.

\begin{tabular}{|c|c|c|c|c|}
\hline \multirow[b]{2}{*}{ Mode } & \multicolumn{2}{|c|}{ Original structure } & \multicolumn{2}{|c|}{$\begin{array}{l}\text { Passive controlled } \\
\text { (8 dampers) }\end{array}$} \\
\hline & $\begin{array}{l}\text { Frequency } \\
\quad(\mathrm{Hz})\end{array}$ & $\underset{(\%)}{\text { Damping ratio }}$ & $\begin{array}{l}\text { Frequency } \\
\quad(\mathrm{Hz})\end{array}$ & $\begin{array}{c}\text { Damping ratio } \\
(\%)\end{array}$ \\
\hline \multicolumn{5}{|c|}{ (a) Vertical part } \\
\hline 1 & 1.48 & 8.00 & 1.87 & 14.91 \\
\hline 2 & 1.58 & 8.00 & 2.02 & 22.80 \\
\hline 3 & 2.02 & 8.00 & 2.20 & 19.99 \\
\hline \multicolumn{5}{|c|}{ (b) Horizontal part } \\
\hline 1 & 0.73 & 3.50 & 0.73 & 3.50 \\
\hline 2 & 1.50 & 3.50 & 1.81 & 15.95 \\
\hline 3 & 2.03 & 3.50 & 2.03 & 3.51 \\
\hline 4 & 2.03 & 3.50 & 2.03 & 3.50 \\
\hline 5 & 2.29 & 3.50 & 2.44 & 3.56 \\
\hline 6 & 2.44 & 3.50 & 2.49 & 11.14 \\
\hline
\end{tabular}

a comparison of the time response of structure before and after control. It means that the single-mode approach technique can translate active control to passive control very well.

From a practical point of view, the roof structure was designed with the implementation of 8 dampers instead of 48 dampers. The state output feedback LQR control was used instead of 


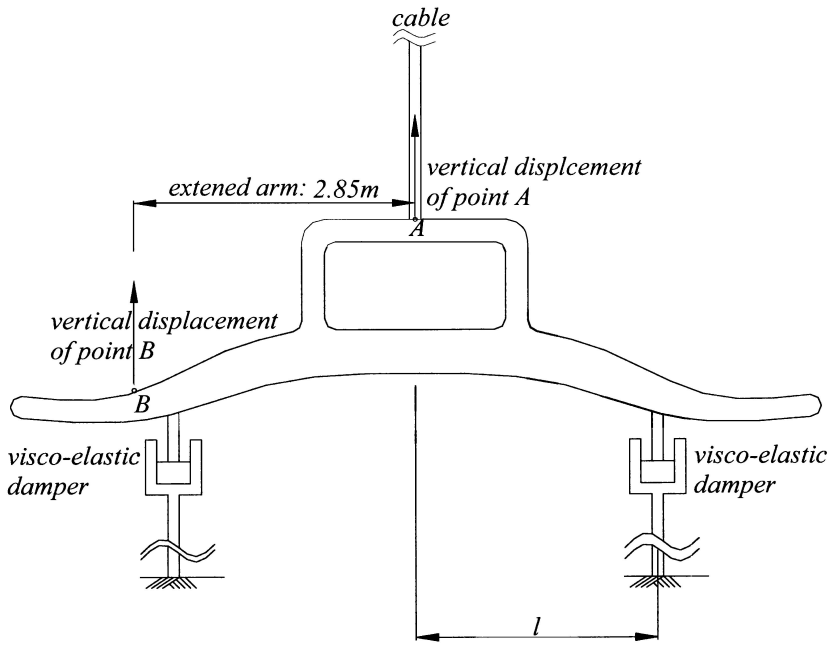

Figure 4. The cross-section diagram in the transverse direction, Chientan station, Taipei Rapid Transit System.

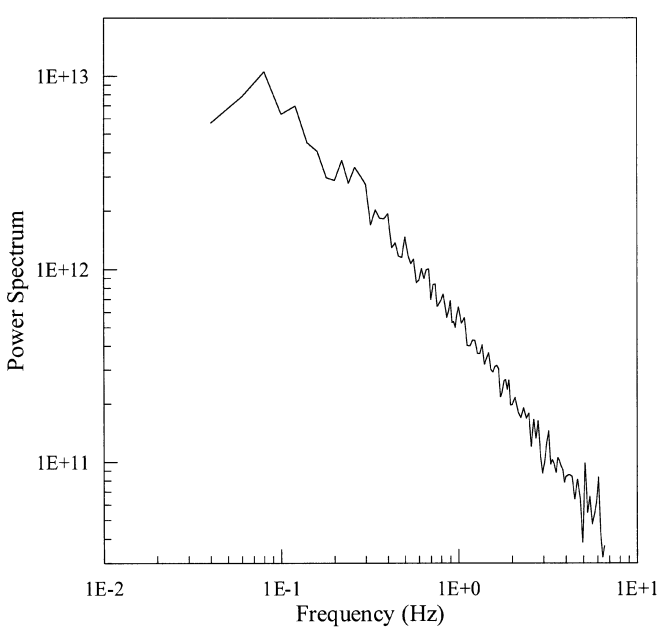

Figure 5. The power spectrum of simulated wind time history $\left(V_{\text {mean }}=40 \mathrm{~m} / \mathrm{s}\right)$.

full-state-feedback control. In this case, eight sensors and eight controllers were used and they just collocated with the passive dampers. The structural parameters and damper coefficients after the implementation of dampers are shown in Tables IV and V, respectively. Figure 10 shows the maximum vertical displacement at the roof centreline for the system with and without control. In addition, Figure 11 shows the maximum vertical displacement at $2.85 \mathrm{~m}$ away from the suspension roof centre under wind load (rotational response included). From the two figures, good control effect was found. 


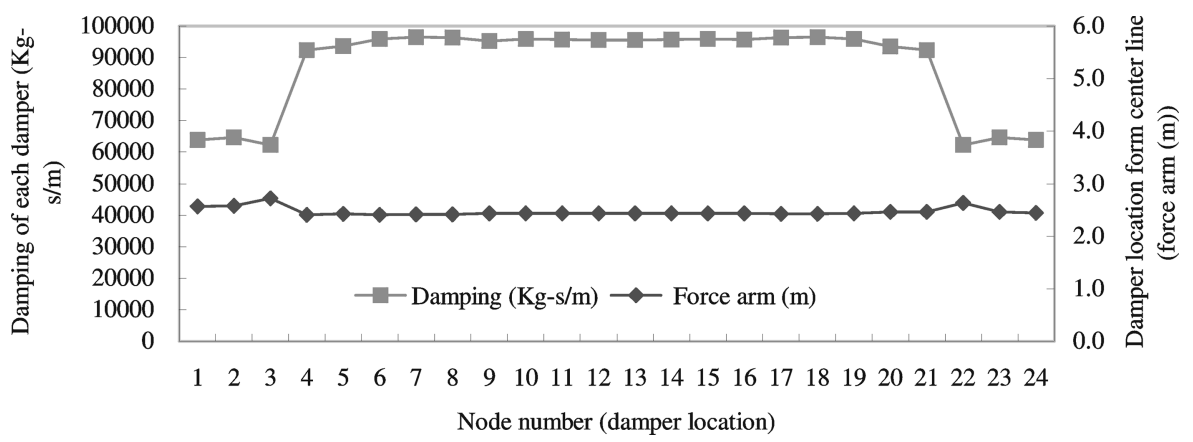

Figure 6. Damper parameter and location of the passive controlled suspension roof system (48 dampers).

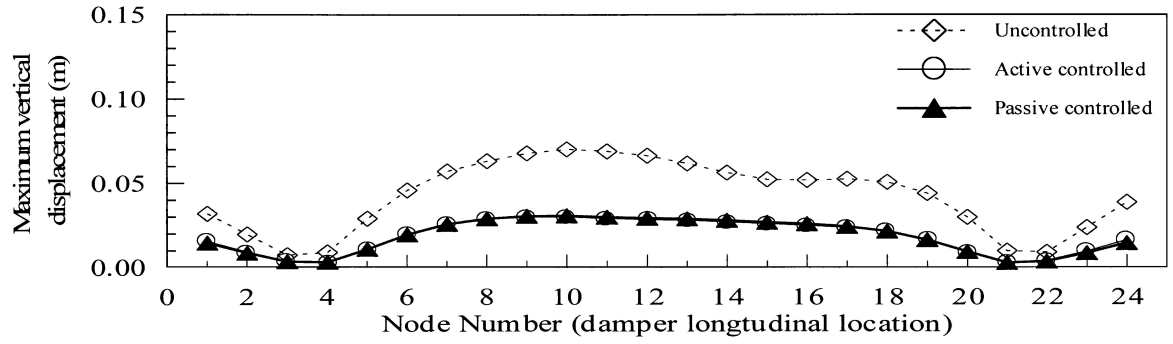

Figure 7. Maximum vertical response at the suspension roof centre (point A at Figure 4) for mean wind velocity $=40(\mathrm{~m} / \mathrm{s})-48$-dampers system.

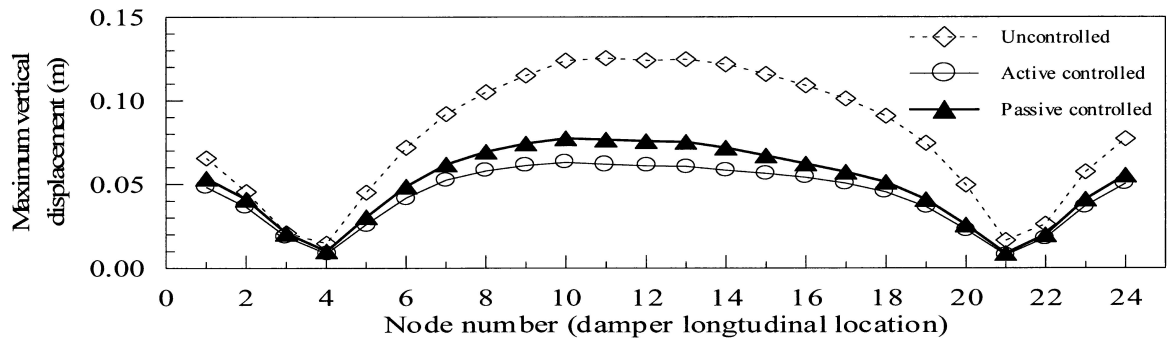

Figure 8. Maximum vertical response at $2.85 \mathrm{~m}$ from the suspension roof centre (point A at Figure 4) for mean wind velocity $=40(\mathrm{~m} / \mathrm{s})-48$-dampers system.

\section{CONCLUSIONS}

The purpose of this study is to conduct the design of dampers (passive control) by using the active-control algorithm and the single-mode approach technique. Through simulation study a building structure with bracing system and a suspension roof with vertical dampers were 


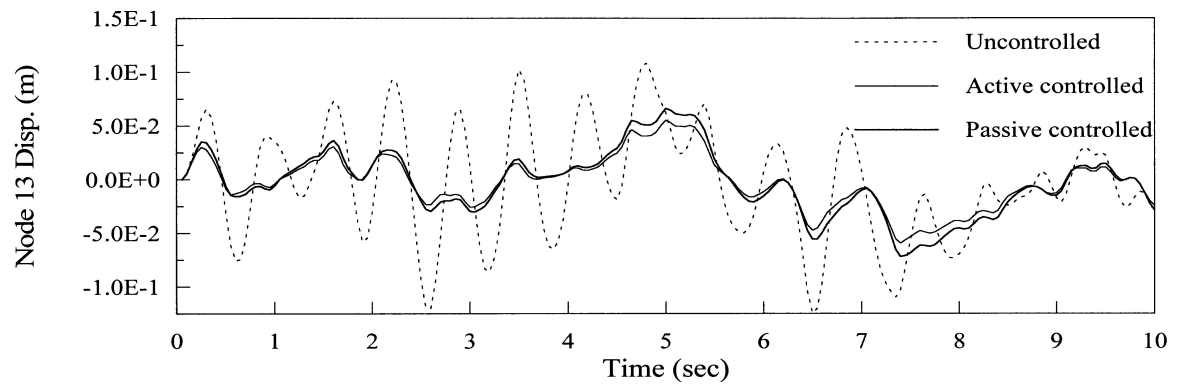

Figure 9. Vertical displacement at $2.85 \mathrm{~m}$ away from the suspension roof centre (point B at Figure 4) for mean wind velocity $=40(\mathrm{~m} / \mathrm{s})$ - 48-dampers system.

Table V. Damping value $(\mathrm{kg} \mathrm{s} / \mathrm{m})$ and transverse location from centreline (force arm, $l$ ) of each damper

(8-damper system).

\begin{tabular}{ccc}
\hline Node no. & Damping $(\mathrm{kg} \mathrm{s} / \mathrm{m})$ & Force $\operatorname{arm} l(\mathrm{~m})$ \\
\hline 8 & $1.22 E+05$ & 1.92 \\
10 & $1.17 E \pm 05$ & 1.95 \\
14 & $1.11 E \pm 05$ & 2.00 \\
16 & $9.83 E \pm 04$ & 2.15 \\
\hline
\end{tabular}

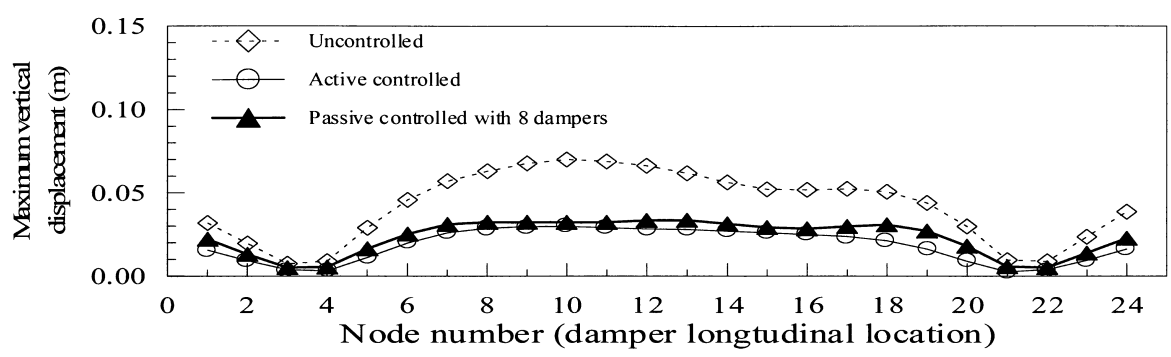

Figure 10. Maximum vertical response at the suspension roof centre (point A at Figure 4) for mean wind velocity $=40(\mathrm{~m} / \mathrm{s})-8$-dampers system.

examined. In this study the following can be concluded:

1. In this study two different active-control algorithms were used to determined the control gains which were be converted to the damping value for passive control of the structure system. The results of control gain from these two methods are different, but two different control algorithms can reach the same control efficiency.

2. As the single-mode approach technique will use single-mode shape to calculate the control parameters (damping coefficient in this study), a separation of coupled and uncoupled modes of system should be made first, if the system is coupled in some modes. 


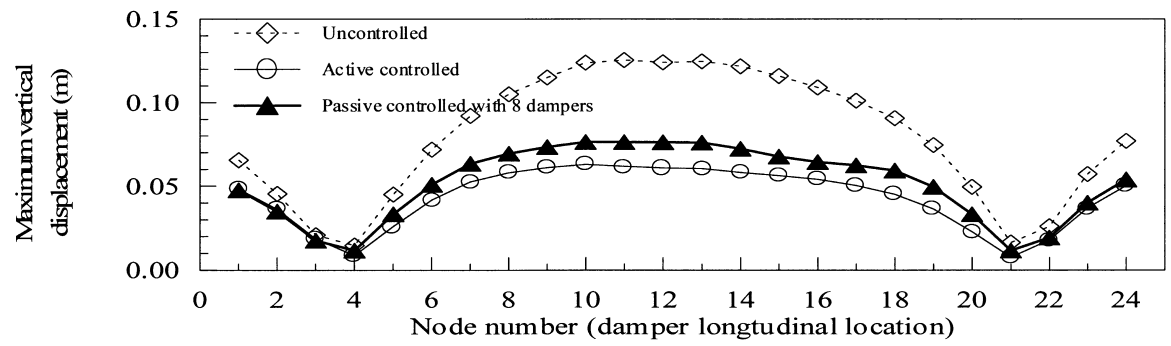

Figure 11. Maximum vertical response at $2.85 \mathrm{~m}$ away from the suspension roof centre (point B at Figure 4) for mean wind velocity $=40(\mathrm{~m} / \mathrm{s})$ - 8-dampers system.

3. In the single-mode approach technique, the lowest mode was always the best choice to use. However, if the system is coupled in two directions, the lowest mode which most participants in the controlled direction is recommended to be used.

4. In this study for the control of building structure, a bracing system with viscoelastic dampers was used. The bracing system provides damping (estimated by optimal control algorithm) only without stiffness. In the real application the bracing system will provide stiffness for the structural system. However, for suspension roof system, the damper stiffness was included in the analysis. By using more modes in damper stiffness formulation, a better control efficiency was found.

\section{ACKNOWLEDGEMENTS}

The authors wish to express their gratitude for the support by National Science Council, Taiwan, under No. NSC 88-2711-3-319-200.

\section{REFERENCES}

1. Mahmoodi P, Robertson LE, Yontar M, Moy Feld I. Performance of viscoelastic dampers in World Trade Center Towers. Dynamics of Structures, Proceedings of the Sessions at Structural Congress '87, Orlando, FL, August 1987.

2. Aiken IA, Kelly JM. Earthquake simulator testing and analytical studies of two energy-absorbing system for multistory buildings. Report No. UCB/EERC-90/03, Earthquake Engineering Research Center, University of California at Berkeley, 1990.

3. Soong TT, Lai ML. Correlation of experimental results with predictions of viscoelastic damping of a modal structure, Proceedings of Damping '91, San Diego, CA, 1991.

4. Chang KC, Soong TT, Lai ML, Nielsen EJ. Development of design procedure for structures with added viscoelastic dampers. Proceedings of the ATC-17-1 Seminar on Seismic Isolation, Passive Energy Dissipation, and Active Control, vol. 2, Applied Technology Council, CA, 1993; 473-484.

5. Shen KL, Soong TT. Modeling of viscoelastic dampers for structural applications. Journal of Engineering Mechanics, ASCE 1995; 112(6): 694-701.

6. Pall A, Venzina S, Proulx P, Pall R. Friction dampers for seismic control of Canadian space agency headquarters. Earthquake Spectra 1993; 9(3): 547-557.

8. Constantinou MC, Symans MD. Experimental and analytical investigation of seismic response of structures with supplemental fluid viscous dampers. Report No. NCEER-92-0032, National Center for Earthquake Engineering Research, State University of New York at Buffalo, 1992.

9. Whittaker A, Bertero V, Alonso J, Thompson C. Earthquake simulator testing of steel plate added damping and stiffness elements. Report No. UCB/EERC-89/02, Earthquake Engineering Research Center, University of California at Berkeley, 1989. 
10. Zhang RH, Soong TT. Seismic design of viscoelastic dampers for structural applications. Journal of Structural Engineering, ASCE 1992; 118(5): 1375-1392.

11. Reinhorn AM, Gluck N, Gluck J, Levy R. Optimal design of supplemental dampers for control of structures. Proceedings of the 11th European Conference on Earthquake Engineering, 1998.

12. Yang JN, Wu JC, Agrawal AK, Hsu SY. Sliding mode control with compensators for wind and seismic response control. Earthquake Engineering and Structural Dynamics 1997; 26: 1137-1156.

13. Wu JC, Yang, JN. LQG and H-infinity control of a TV transmission tower under stochastic winds. Proceedings of the International Conference on Structural Safety and Reliability, Kyoto, Japan, 1997.

14. Loh CH, Lin PY, Wu JC, Yang JN. Experimental verification of static-output-feedback control for a seismic-excited full scale building. 2 WCSC, Kyoto, June 1998.

15. Chung LL, Reihorn AM, Soong TT. Experiment on Active control of Seismic Structures. Journal of Engineering Mechanics, ASCE 1988; 114(2): 241-256. 